\title{
Efficient spin-spin scalar coupling mediated C-13 homonuclear polarization transfer in biological solids without proton decoupling
}

\author{
Yun Mou, John Chin Hao Chao, Jerry C.C. Chan* \\ Department of Chemistry, National Taiwan University, No. 1, Section 4, Roosevelt Road, Taipei, Taiwan \\ Received 10 August 2005; received in revised form 5 October 2005 \\ Available online 10 November 2005
}

\begin{abstract}
We demonstrate that an efficient $\mathrm{C}^{\prime} \leftrightarrow \mathrm{C}_{\alpha}$ polarization transfer based on J-coupling can be realized under fast magic-angle spinning (MAS) condition without ${ }^{1} \mathrm{H}$ decoupling. Experimental results are presented for model crystalline compounds as well as a non-crystalline 17-residue polypeptide $\mathrm{MB}(i+4) \mathrm{EK}$. Measurements on $\mathrm{MB}(i+4) \mathrm{EK}$ demonstrate that $53 \%$ of the initial $\mathrm{C}^{\prime}$ polarization was transferred to the cross peaks at $7.05 \mathrm{~T}$ under $25 \mathrm{kHz}$ MAS spinning.

(C) 2005 Elsevier Inc. All rights reserved.
\end{abstract}

Keywords: MAS; Polarization transfer; TOBSY; J-coupling; Scalar coupling; Polypeptide

\section{Introduction}

In the past few years, it has been shown that solid-state nuclear magnetic resonance (SSNMR) is indispensable for the structural elucidation of non-crystalline biological solids [1]. Under the high-resolution condition provided by magic-angle spinning (MAS), it is possible to probe the correlations between different nuclei via the dipole-dipole interaction or the spin-spin scalar coupling (J-coupling) $[2,3]$. In particular, it is of great interest to pursue $\mathrm{J}$ coupling mediated polarization transfer in SSNMR [4-16] both because of the selectivity offered by this through-bond interaction and because of the $100 \%$ theoretical transfer efficiency for a two-spin system. However, typical ${ }^{13} \mathrm{C}^{-13} \mathrm{C}$ polarization transfer efficiency reported for polypeptides is significantly less than the theoretical maximum. The major reason is due to the requirement of high power ${ }^{1} \mathrm{H}$ decoupling during the polarization transfer. Recently, we have developed a pulse sequence with the acronym RTOBSY for the J-coupling mediated polarization transfer in phosphorus containing inorganic systems [12,17-19]. Because the decoupling field is usually set to be three times

\footnotetext{
${ }^{*}$ Corresponding author. Fax: +886223636359.

E-mail address: chanjcc@ntu.edu.tw (J.C.C. Chan).
}

larger than the recoupling field in a typical recoupling experiment $[20,21]$ the R-TOBSY sequence with ${ }^{1} \mathrm{H}$ decoupling was found to be of limited use in biological systems under fast MAS condition (data not shown).

Many years ago, Yannoni et al. demonstrated that separate proton decoupling is in principle unnecessary for the ${ }^{13} \mathrm{C}$ nutation spectroscopy [22]. Recently, it has been shown in a ${ }^{13} \mathrm{C}$ homonuclear dipolar recoupling experiment that MAS alone is sufficient for a good ${ }^{1} \mathrm{H}$ decoupling when the spinning frequency is high enough [23]. A systematic study has also shown that significant excitation of ${ }^{13} \mathrm{C}$ homonuclear double-quantum coherence can be acquired without ${ }^{1} \mathrm{H}$ decoupling [24]. Therefore, we surmise that the TOBSY-like sequences originally developed by Meier and co-workers may be applied for the study of polypeptides under fast MAS condition without ${ }^{1} \mathrm{H}$ decoupling. Consequently, we demonstrate in this work that scalar coupling mediated polarization transfer does not require ${ }^{1} \mathrm{H}$ decoupling under the condition of fast MAS. Measurements on the 17-residue $\alpha$-helical noncrystalline peptide $\mathrm{MB}(i+4) \mathrm{EK}$ demonstrate that $53 \%$ of the initial $\mathrm{C}^{\prime}$ polarization was transferred to the cross peaks at $7.05 \mathrm{~T}$ under $25 \mathrm{kHz}$ MAS spinning. It is noteworthy that the alleviation of high power ${ }^{1} \mathrm{H}$ decoupling can help limit power deposition in the biological sample under study. 


\section{Experimental}

\subsection{Sample preparation}

$\left[\mathrm{U}_{-}{ }^{13} \mathrm{C},{ }^{15} \mathrm{~N}\right]$-alanine and $\left[\mathrm{U}_{-}{ }^{13} \mathrm{C},{ }^{15} \mathrm{~N}\right]$-valine were purchased from Cambridge Isotopes Laboratories. The peptide $\mathrm{MB}(i+4) \mathrm{EK}$ (sequence Ac-AEAAAKEAAAKEAAAKA- $\mathrm{NH}_{2}$ ) was synthesized using standard FMOC solid-phase methods on a Perkin-Elmer/Applied Biosystems model $433 \mathrm{~A}$ peptide synthesizer, with uniform ${ }^{13} \mathrm{C}$ and ${ }^{15} \mathrm{~N}$ labeling of lysine at position 6 (Lys6) and alanine at position 9 (Ala9). Purification was accomplished with preparative scale HPLC, using a reverse-phase C18 column. The purity of the product was checked by ESIMS and the sample was subsequently lyophilized for NMR measurements.

\subsection{Solid-state NMR}

All NMR experiments were carried out at $7.05 \mathrm{~T}$ on a Bruker DSX300 NMR spectrometer equipped with a $2.5 \mathrm{~mm}$ double-resonance probe. The spectra were measured at a spinning frequency of $25 \mathrm{kHz} .{ }^{13} \mathrm{C}$ chemical shifts were referenced to TMS using adamantane as the secondary standard. During the CP contact time $(1.5 \mathrm{~ms})$ the ${ }^{1} \mathrm{H}$ nutation frequency was set to $50 \mathrm{kHz}$ and that of ${ }^{13} \mathrm{C}$ was ramped linearly through the Hartmann-Hahn matching sideband. Recycle delay was set to $4 \mathrm{~s}$. The $\pi / 2$ Gaussian selective pulse was set to 475 and $280 \mu$ s long for $\left[\mathrm{U}_{-}{ }^{13} \mathrm{C},{ }^{15} \mathrm{~N}\right]$-alanine and $\left[\mathrm{U}_{-}{ }^{13} \mathrm{C},{ }^{15} \mathrm{~N}\right]$-valine, respectively. The pulse sequence used for the measurements of the $\mathrm{MB}(i+4) \mathrm{EK}$ sample is shown in Fig. 1. For the R-TOBSY pulse block, the ${ }^{13} \mathrm{C}$ nutation frequency was set to $125 \mathrm{kHz}$. The R-TOBSY mixing time was set to $9.6 \mathrm{~ms}$. No super-

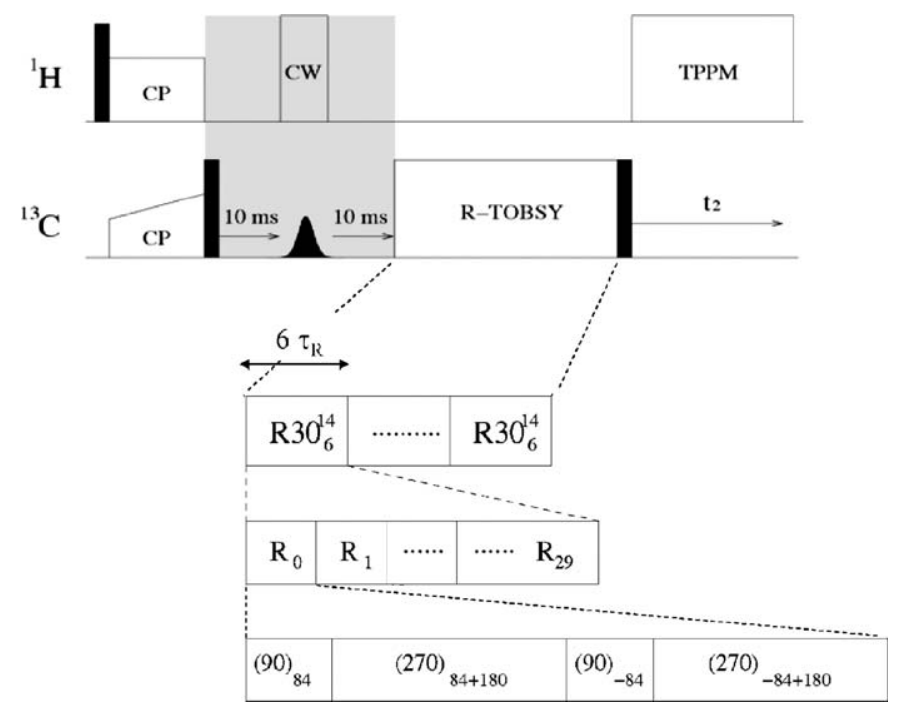

Fig. 1. Pulse sequence for the measurements on model compounds. Black rectangular blocks represent $\pi / 2$ pulses. The Gaussian-shaped pulse is a selective $\pi / 2$ pulse positioned in the aliphatic region. The shaded part is to be replaced by $t_{1}$ evolution and then a $\pi / 2$ flip-back pulse in the $2-\mathrm{D}$ analogue. cycle was used. Proton TPPM decoupling during the acquisition period was set to $100 \mathrm{kHz}$.

Quadrature detection for 2D spectra in the F1 dimension was achieved by the hypercomplex approach. Spectral artifacts are suppressed by inverting the phase of the flipback ${ }^{13} \mathrm{C} \pi / 2$ pulse and alternating addition and subtraction of FID signals. Together with CYCLOPS our phase cycling has a total of eight steps. For each $t_{1}$ increment 88 transients were accumulated, and a total of 256 increments were done at steps of one rotor period. To reduce the sample heating due to fast MAS spinning, a stream of dry cooling air at $-11^{\circ} \mathrm{C}(800 \mathrm{~L} / \mathrm{h})$ was used to keep the sample temperature at around $30^{\circ} \mathrm{C}$, calibrated by measurements on lead (II) nitrate. Consequently, the stability of the spinning frequency is slightly deteriorated $( \pm 10 \mathrm{~Hz})$.

\subsection{Numerical simulation}

All numerical studies in this work were carried out using SIMPSON (version 1.1.0.) [25]. For our simulations, the maximum time step over which the Hamiltonian is approximated to be time-independent was set to $1.0 \mu \mathrm{s}$. Typically, a powder averaging scheme containing 320 REPULSION angles $(\alpha$ and $\beta)$ and $36 \gamma$ angles was chosen [26]. Relaxation effects were ignored. The spin cluster used for simulations was constructed based on the structural parameters of alanine. There are three carbons $\left(\mathrm{C}^{\prime}, \mathrm{C}_{\alpha}, \mathrm{C}_{\beta}\right)$ and one proton $\left(\mathrm{H}_{\alpha}\right)$ in the spin cluster. The J-coupling constants between $\mathrm{C}^{\prime} / \mathrm{C}_{\alpha}$ and $\mathrm{C}_{\alpha} / \mathrm{C}_{\beta}$ were set to 50 and $35 \mathrm{~Hz}$, respectively. For simplicity, the orientations of CSA tensors with respect to the dipolar framework were set arbitrarily. The simulation was done based on the $\mathrm{R}$ TOBSY sequence. Initially the polarizations of $\mathrm{C}_{\alpha}$ and $\mathrm{C}_{\beta}$ were nullified. Other simulation parameters were matched to the experimental conditions.

\section{Results and discussion}

Referring to the data measured for $\left[\mathrm{U}_{-}{ }^{13} \mathrm{C},{ }^{15} \mathrm{~N}\right]$-alanine shown in Fig. 2a, the maximum ${ }^{13} \mathrm{C}_{\alpha}$ and ${ }^{13} \mathrm{C}_{\beta}$ peak intensities (normalized by the initial $\mathrm{C}^{\prime}$ intensity) are found at the mixing times of 8.64 and $14 \mathrm{~ms}$, respectively. Because typical J-coupling constants for $\mathrm{C}^{\prime}-\mathrm{C}_{\alpha}$ and $\mathrm{C}_{\alpha}-\mathrm{C}_{\beta}$ spin pairs are about 50 and $35 \mathrm{~Hz}$, respectively, our data show that $\mathrm{J}$-coupling is indeed the predominant mechanism for the polarization transfer. This interpretation is also corroborated by numerical simulations shown in Fig. 2a. The agreement between the experimental (symbols) and simulation data (lines) is excellent. Experimentally, $74 \%$ of the initial $\mathrm{C}^{\prime}$ polarization has been transferred to $\mathrm{C}_{\alpha}$ and $\mathrm{C}_{\beta}$ at the mixing time of $8.64 \mathrm{~ms}$, for which the raw spectra are shown in Fig. 2c. The decay of the total polarization remains less than $10 \%$ through out the experiment. Fig. $2 \mathrm{~b}$ shows the results obtained for $\left[\mathrm{U}_{-}{ }^{13} \mathrm{C},{ }^{15} \mathrm{~N}\right]$-valine. Although at mixing time equal to $0 \mathrm{~ms}$ there are some residual $\mathrm{C}_{\alpha}$ and $\mathrm{C}_{\gamma}$ signals due to pulse imperfection, the overall results are consistent with what we obtained for 

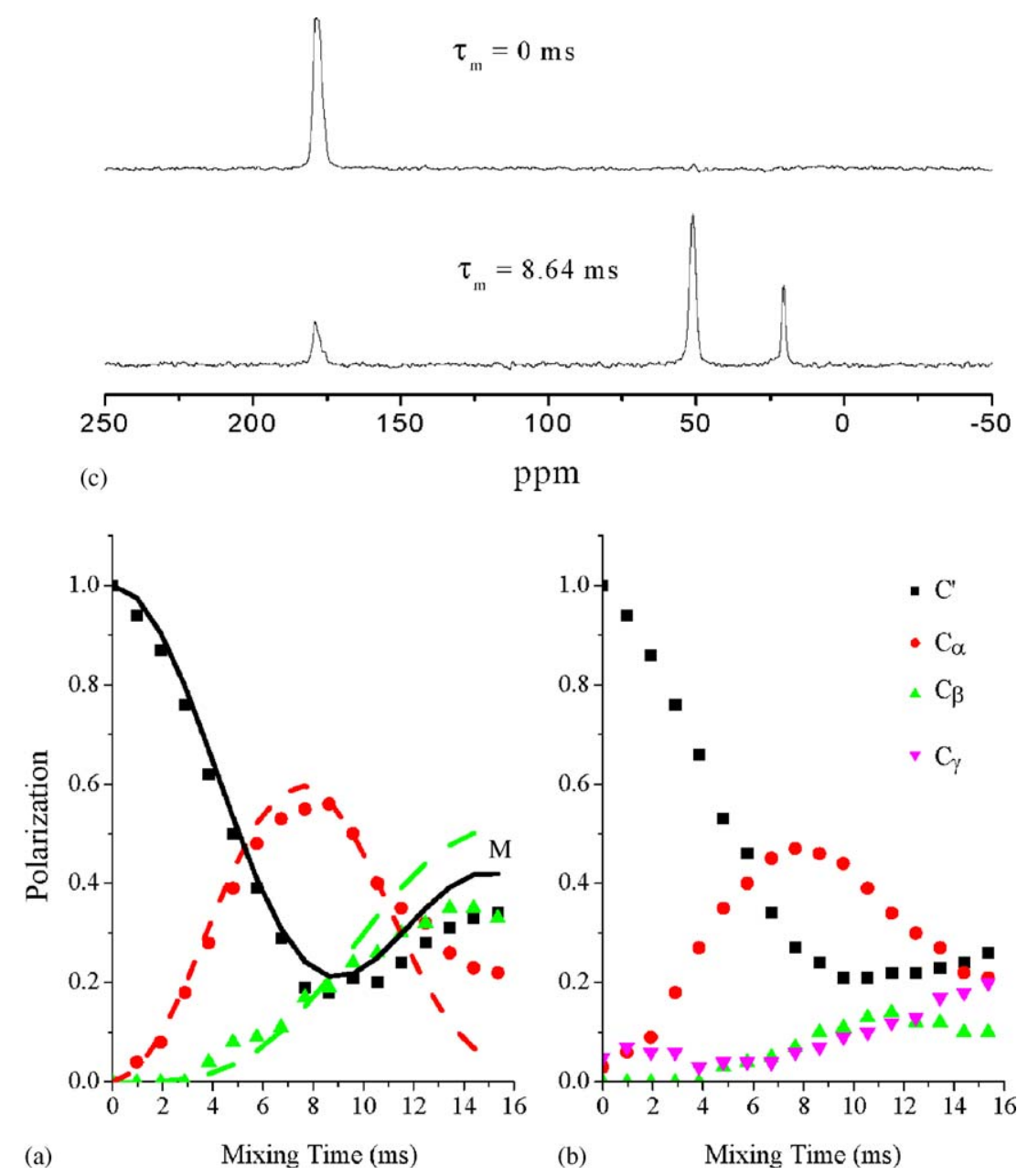

Fig. 2. Plot of peak intensities of different carbon species as a function of mixing time for (a) $\left[\mathrm{U}_{-}{ }^{13} \mathrm{C},{ }^{15} \mathrm{~N}\right]$-alanine and (b) $\left[\mathrm{U}_{-}{ }^{13} \mathrm{C}\right.$, $\left.{ }^{15} \mathrm{~N}\right]-\mathrm{valine}$. The ${ }^{13} \mathrm{C}$ spectra in (c) were obtained for $\left[\mathrm{U}_{-}^{13} \mathrm{C},{ }^{15} \mathrm{~N}\right]$-alanine with mixing times $\left(\tau_{\mathrm{m}}\right)$ equal to 0 and $8.64 \mathrm{~ms}$. The lines in (a) denote the results of numerical simulations.

$\left[\mathrm{U}_{-}{ }^{13} \mathrm{C},{ }^{15} \mathrm{~N}\right]$-alanine. Additional measurements show that the transfer efficiency will be significantly attenuated if proton decoupling is applied during the mixing time even when the Hartmann-Hahn matching condition has been avoided (data not shown). To verify that such high transfer efficiency is not due to relaxation effects, we also measured the two-dimensional ${ }^{13} \mathrm{C}-{ }^{13} \mathrm{C}$ correlation spectrum for $\left[\mathrm{U}-{ }^{13} \mathrm{C},{ }^{15} \mathrm{~N}\right]$-alanine (Fig. 3a). The pulse sequence in Fig. 1 was hence modified by replacing the shaded part by a $t_{1}$ evolution with ${ }^{1} \mathrm{H}$ TPPM decoupling [27] followed by a $\pi / 2$ flip-back pulse. The mixing time was set to $9.6 \mathrm{~ms}$. For comparison, we also measured a control spectrum where the ${ }^{13} \mathrm{C}$ rf power was nullified during the polarization transfer period (Fig. 3b). After normalizing the cross-peak intensities by the $\mathrm{C}^{\prime}$ signal of the control spectrum, we obtain an overall $\mathrm{C}^{\prime} \rightarrow\left\{\mathrm{C}_{\alpha}, \mathrm{C}_{\beta}\right\}$ and $\mathrm{C}_{\alpha} \rightarrow\left\{\mathrm{C}^{\prime}, \mathrm{C}_{\beta}\right\}$ transfer efficiency of $69 \%$ and $66 \%$, respectively. As expected, the total magnetization decayed to $89 \%$ of the control signal.

As a stringent test case, we measured the ${ }^{13} \mathrm{C}-{ }^{13} \mathrm{C}$ correlation spectrum for a 17-residue non-crystalline polypeptide with uniform ${ }^{13} \mathrm{C}$ and ${ }^{15} \mathrm{~N}$ labeling of lysine at position 6 (Lys6) and alanine at position 9 (Ala9). The 17-residue peptide $\mathrm{MB}(i+4) \mathrm{EK}$ has been shown to be highly $\alpha$-helical [28-30]. To check the tolerance of our pulse sequence with respect to $\mathrm{rf}$ inhomogeneity, we purposely confined the sample in the bottom $1 / 2$ of the rotor volume using Teflon spacers. Fig. 4 shows the correlation spectrum obtained with a mixing time of $9.6 \mathrm{~ms}$. The total experimental time was $25 \mathrm{~h}$. By comparison with the control spectrum, we obtain a $\mathrm{C}^{\prime} \rightarrow\left\{\mathrm{C}_{\text {aliphatic }}\right\}$ transfer efficiency of $53 \%$ and the total magnetization decayed to $80 \%$ of the control signal. The superb transfer efficiency can also be appreciated by visual inspection of the projection shown in Fig. 4, in which the $\mathrm{C}^{\prime}-\mathrm{C}_{\alpha}$ cross-peak intensity is larger than that of the diagonal $\mathrm{C}^{\prime}$ signal.

\section{Conclusion}

In this work we have resolved two important issues. Firstly, we have achieved a good ${ }^{13} \mathrm{C}^{13} \mathrm{C}$ polarization transfer efficiency in a uniformly labeled non-crystalline polypeptide, demonstrating the applicability of our 

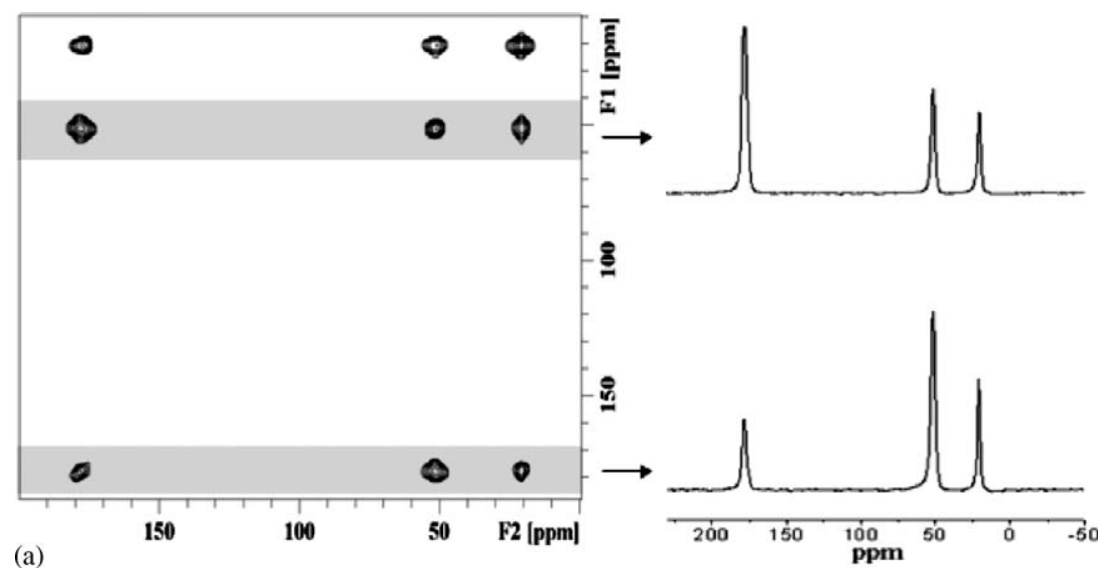

(a)
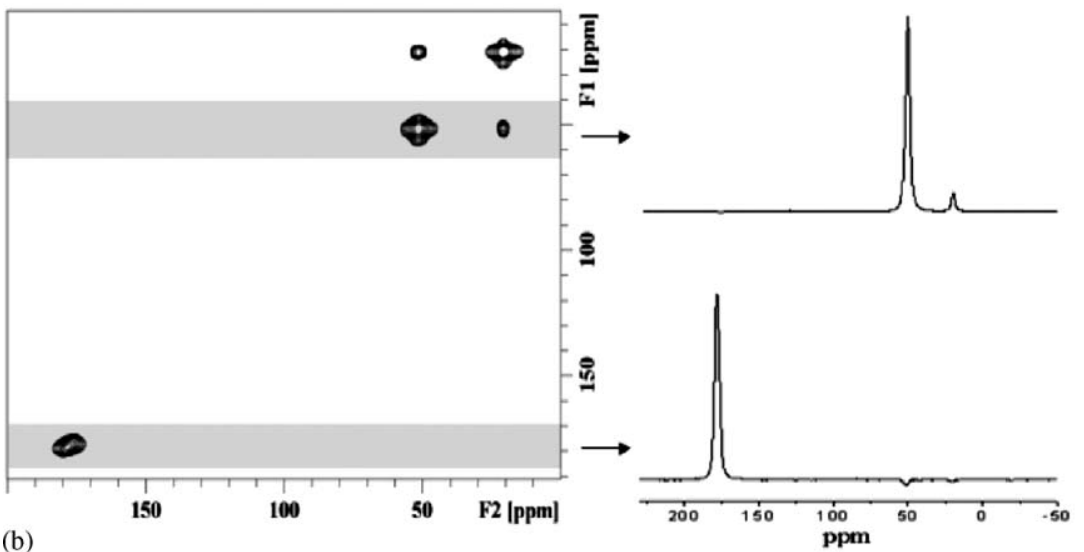

Fig. 3. (a) ${ }^{13} \mathrm{C}-{ }^{13} \mathrm{C}$ two-dimensional correlation spectra measured for $\left[\mathrm{U}_{-}{ }^{13} \mathrm{C},{ }^{15} \mathrm{~N}\right]$-alanine. Mixing time was set equal to $9.6 \mathrm{~ms}$. (b) Control spectrum measured for $\left[\mathrm{U}-{ }^{13} \mathrm{C},{ }^{15} \mathrm{~N}\right]$-alanine, where the rf power of the ${ }^{13} \mathrm{C}$ channel was nullified during the R-TOBSY mixing period.

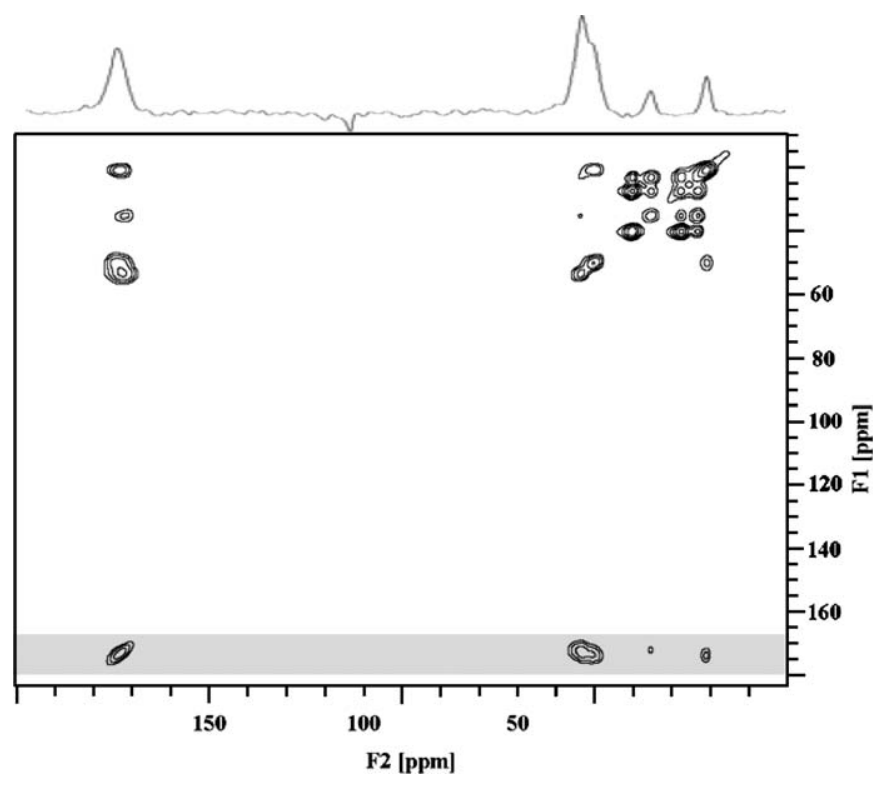

Fig. $4 .{ }^{13} \mathrm{C}-{ }^{13} \mathrm{C}$ correlation spectrum measured for the $\mathrm{MB}(i+4) \mathrm{EK}$ polypeptides at $7.05 \mathrm{~T}$ under $25 \mathrm{kHz}$ MAS spinning. The projection of the shaded region is shown to highlight the excellent $\mathrm{C}^{\prime} \rightarrow \mathrm{C}_{\alpha}$ transfer efficiency. approach to the studies of real biological systems. Secondly, we show that a simultaneous high power ${ }^{1} \mathrm{H}$ decoupling is NOT necessary for J-coupling mediated ${ }^{13} \mathrm{C}-{ }^{13} \mathrm{C}$ polarization transfer. Although we do not have access to a high-field magnet to further evaluate the performance of our approach, numerical simulation does show that the same transfer efficiency can be achieved in $18.8 \mathrm{~T}$. This no-decoupling approach, coined as NO-DEC by Baldus and co-workers [24], was first tested for dipolar recoupling experiments and it was shown that removing proton decoupling will somewhat attenuate the transfer efficiency to a lower value. Our work, on the other hand, shows that it is necessary to switch off the proton decoupling to achieve a good transfer efficiency for J-coupling-based transfer. We believe that this NO-DEC approach is quite general and can be immediately incorporated into most existing TOBSY-like sequences $[5,6,10,11,13]$. Altogether, we anticipate that J-coupling mediated polarization transfer can find fruitful applications in many structural problems involving non-crystalline solids and systems with significant dynamics. 


\section{Acknowledgments}

This work was supported by grants from the National Science Council and the Ministry of Education.

\section{References}

[1] R. Tycko, Prog. Nucl. Magn. Reson. Spectrosc. 42 (2003) 53-68.

[2] M. Baldus, Prog. Nucl. Magn. Reson. Spectrosc. 41 (2002) 1-47.

[3] I. Schnell, Prog. Nucl. Magn. Reson. Spectrosc. 45 (2004) 145-207.

[4] A. Ramamoorthy, T. Fujiwara, K. Nagayama, J. Magn. Reson. A 104 (1993) 366-368.

[5] M. Baldus, B.H. Meier, J. Magn. Reson. A 121 (1996) 65-69.

[6] M. Baldus, R.J. Iuliucci, B.H. Meier, J. Am. Chem. Soc. 119 (1997) 1121-1124.

[7] A. Lesage, C. Auger, S. Caldarelli, L. Emsley, J. Am. Chem. Soc. 119 (1997) 7867-7868.

[8] R. Verel, J. van Beek, B.H. Meier, J. Magn. Reson. 140 (1999) $300-303$.

[9] A. Lesage, M. Bardet, L. Emsley, J. Am. Chem. Soc. 121 (1999) 10987-10993.

[10] A.S.D. Heindrichs, H. Geen, C. Giordani, J.J. Titman, Chem. Phys. Lett. 335 (2001) 89-96.

[11] E.H. Hardy, R. Verel, B.H. Meier, J. Magn. Reson. 148 (2001) 459-464.

[12] J.C.C. Chan, G. Brunklaus, Chem. Phys. Lett. 349 (2001) 104-112.

[13] E.H. Hardy, A. Detken, B.H. Meier, J. Magn. Reson. 165 (2003) 208-218.
[14] M. Ernst, A. Detken, A. Bockmann, B.H. Meier, J. Am. Chem. Soc. 125 (2003) 15807-15810.

[15] L.J. Mueller, D.W. Elliott, G.M. Leskowitz, J. Struppe, R.A. Olsen, K.-C. Kim, C.A. Reed, J. Magn. Reson. 168 (2004) 327-335.

[16] L. Duma, W.C. Lai, M. Carravetta, L. Emsley, S.P. Brown, M.H Levitt, ChemPhysChem 5 (2004) 815-833.

[17] S. Reiser, G. Brunklaus, J.H. Hong, J.C.C. Chan, H. Eckert, A. Pfitzner, Chem. Eur. J. 8 (2002) 4228-4233.

[18] G. Brunklaus, J.C.C. Chan, H. Eckert, Z. Phys. Chem. 217 (2003) 1627-1639.

[19] G. Brunklaus, J.C.C. Chan, H. Eckert, S. Reiser, T. Nilges, A. Pfitzner, Phys. Chem. Chem. Phys. 5 (2003) 3768-3776.

[20] Y. Ishii, J. Ashida, T. Terao, Chem. Phys. Lett. 246 (1995) 439-445.

[21] A.E. Bennett, C.M. Rienstra, J.M. Griffiths, W.G. Zhen, P.T. Lansbury, R.G. Griffin, J. Chem. Phys. 108 (1998) 9463-9479.

[22] C.S. Yannoni, R.D. Kendrick, J. Chem. Phys. 74 (1981) 747-749.

[23] Y. Ishii, J. Chem. Phys. 114 (2001) 8473-8483.

[24] C.E. Hughes, S. Luca, M. Baldus, Chem. Phys. Lett. 385 (2004) 435-440.

[25] M. Bak, J.T. Rasmussen, N.C. Nielsen, J. Magn. Reson. 147 (2000) 296-330.

[26] M. Bak, N.C. Nielsen, J. Magn. Reson. 125 (1997) 132-139.

[27] A.E. Bennett, C.M. Rienstra, M. Auger, K.V. Lakshmi, R.G. Griffin, J. Chem. Phys. 103 (1995) 6951-6958.

[28] F.J. Blanco, R. Tycko, J. Magn. Reson. 149 (2001) 131-138.

[29] H.W. Long, R. Tycko, J. Am. Chem. Soc. 120 (1998) 7039-7048.

[30] J.C.C. Chan, R. Tycko, J. Am. Chem. Soc. 125 (2003) 11828-11829. 